\title{
Preoperative anemia and total hospitalization time are the independent factors of preoperative deep venous thromboembolism in Chinese elderly undergoing hip surgery
}

\author{
Long Feng ${ }^{1,2}$, Longhe $X^{3}$, Weixiu Yuan ${ }^{2}$, Zhipeng $X^{3}$, Zeguo Feng ${ }^{3 *}$ and Hong Zhang ${ }^{1,3^{*}}$
}

\begin{abstract}
Background: This study was designed to explore the prevalence and risk factors of preoperative deep venous thromboembolism (DVT) in Chinese elderly with hip fracture.

Methods: From January 1, 2012, to December 31, 2018, 273 elderly patients over 70 years old with elective hip surgery were collected from the electronic medical records. Collected data included demographic characteristics, comorbidities, ASA classification, types of previous operations, types of anesthesia, operation time, fracture to operation time, preoperative hemoglobin level, anemia, blood-gas analysis, cardiac function, whether transfusion, preoperative hospitalization, postoperative hospitalization, electrocardiograph, lower limb venous ultrasonography and total hospitalization time.

Results: In these 273 patients, 15(5.6\%) had ultrasonography evidence of DVT in affected limbs before surgery. Three of all patients received an temporary inferior vena cave filter placement preoperatively. Fracture to surgery time, preoperative hemoglobin level, anemia, preoperative hospitalization, pulmonary disease and total hospitalization time were statistically different between DVT group and non-DVT group ( $P<0.05$ for all). Moreover, preoperative anemia (OR: 0.144, 95\%Cl: 0.026$0.799, P=0.027)$ and total hospitalization time (OR: $1.135 ; 95 \% \mathrm{Cl}: 1.023-1.259, P=0.017)$ were the two independent risk factors for preoperative DVT.

Conclusion: Preoperative anemia and total hospitalization time were independent risk factors for venous DVT in Chinese elderly with hip fracture.
\end{abstract}

Keywords: Anesthesia, Deep vein thrombosis, Hip fracture, Hospitalization time, Anemia

\section{Background}

Venous thromboembolism (VTE) including deep vein thrombosis (DVT) and pulmonary embolism (PE) is a serious and preventable complication after hip fracture [1-4].

\footnotetext{
*Correspondence: Beijing_301@sina.com; mazuimao301@163.com

${ }^{3}$ Department of Anesthesia Operation Center, Chinese PLA General Hospital, No.28, Fuxing Road, Beijing 100853, China

'Medicine School of Chinese PLA, No.28, Fuxing Road, Beijing 100853, China Full list of author information is available at the end of the article
}

The risk for VTE among patients undergoing major orthopedic surgery, particularly hip fracture surgery, is the highest among all surgical patients. It has been reported that preoperative DVT had an incidence of $6-9 \%$ in patients with hip fracture receiving surgery within the $48 \mathrm{~h}$, whereas the rate could be raised to $54.5-62 \%$ when there was a delay for more than $48 \mathrm{~h} \mathrm{[5].} \mathrm{Pedersen} \mathrm{et} \mathrm{al.} \mathrm{[6]} \mathrm{have}$ proposed that hip fracture was associated with increased subsequent risk of VTE in a population-based cohort

(c) The Author(s). 2020 Open Access This article is licensed under a Creative Commons Attribution 4.0 International License, which permits use, sharing, adaptation, distribution and reproduction in any medium or format, as long as you give appropriate credit to the original author(s) and the source, provide a link to the Creative Commons licence, and indicate if changes were made. The images or other third party material in this article are included in the article's Creative Commons licence, unless indicated otherwise in a credit line to the material. If material is not included in the article's Creative Commons licence and your intended use is not permitted by statutory regulation or exceeds the permitted use, you will need to obtain permission directly from the copyright holder. To view a copy of this licence, visit http://creativecommons.org/licenses/by/4.0/ The Creative Commons Public Domain Dedication waiver (http://creativecommons.org/publicdomain/zero/1.0/) applies to the data made available in this article, unless otherwise stated in a credit line to the data. 
study of 110,563 patients with incident hip fracture. The risk of VTE increased 17-fold in the first 30 days after hip fracture, declining to a 2.1 fold increase from 31 to 365 days following hip fracture. Risk factors for VTE include age, obesity, chronic obstructive pulmonary disease (COPD), atrial fibrillation, anemia, depression, trauma, total knee arthroplasty, hypercoagulable states and postoperative complications [7]. Shahi et al. [8] have also pointed out that the advanced age (greater than 70 years old, OR: 1.3, 95\% CI:1.1-1.4) is the risk factors for developing in-hospital VTE. However, limited studies has been performed to observe the risk factors of preoperative DVT in Chinese elderly over 70 years old with hip fracture. Thus, the purpose of this study was to explore the prevalence and risk factors of preoperative DVT in Chinese elderly over 70 years old with hip fracture.

\section{Methods}

This retrospective single-center study included 273 consecutive patients over 70 years old with hip fracture and elective surgery in Hainan Hospital of Chinese People's Liberation Army General Hospital from January 1, 2012 to December 31, 2018. Exclusion criteria for this study included age $<70$ years, multi-type of fracture and conservation treatment (Fig. 1). All data were collected from the electronic medical records. Collected data included demographic characteristics, comorbidities (including diabetes, hypertension, stroke, ischemic heart disease, arrhythmia, congestive heart failure, and COPD), hemoglobin level, erythrocyte sedimentation (ESR), D-dimer, ASA classification, types of surgeries, types of anesthesia, preoperative hospitalization, postoperative hospitalization, whether transfusion, operation time, fracture to operation time, preoperative hemoglobin level, anemia (the anemia was defined as hemoglobin below $120 \mathrm{~g} / \mathrm{dL}$ in male and $110 \mathrm{~g}$ / dL in female), blood-gas analysis, cardiac function, electrocardiograph, preoperative lower limb venous ultrasonography and hospitalization time. Types of hip fractures included the femoral neck, intertrochanteric, subtrochanteric, and proximal shaft fractures.
Performed surgeries included hip replacement and fixation procedures. All patients with hip fractures were routinely treated with a low molecular weight heparin sodium daily to prevent DVT after hospitalization. In addition, all patients underwent routine ultrasound examination of the lower extremities before surgery and before discharge. DVTs were classified into three types: central type, peripheral type, and mixed type. Central type referred to thrombus occurring proximal to the knee in the iliacs, superficial femoral and/or femoral veins. Peripheral type was defined as thrombosis distal to the knee in the posterior tibial veins or peroneal veins. DVT was classified as mixed type when involving the whole deep venous system of lower limb. Ultrasonography of lower limb veins was usually performed again before leave hospital. The diagnosis of DVT was according to Robinov criterion, which are included the following four parts: 1 . In constant filling defects, thrombi are constant in appearance, and tend to be sharply delineated; 2. Abrupt termination of the opaque column occurs at a constant site in a vain, either above or below the obstruction; 3. Nonfilling of the entire deep system or portions thereof when proper technique is used is abnormal and usually due to phlebitis; 4 . Diversion of flow, representing collateral flow, is the counterpart if the nonfilling described above [9]. Besides, the anemia in this study was defined as hemoglobin below $120 \mathrm{~g} / \mathrm{dL}$ in male and $110 \mathrm{~g} / \mathrm{dL}$ in female.

\section{Statistically analysis}

Continuous data were presented as the means and standard deviations (SD). Categorical data were presented as the numbers and percentages. By comparing the DVT group with the non-DVT group, when performing univariate logistic regression analysis when $P$ values $<0.05$ is a risk factor. When the factors $P$ values is $<0.1$, a multivariate analysis is performed. These risk factors were then included in multivariate logistic regression analyses to detect the risk factors independently affecting the DVT. Odds ratios were displayed with a 95\% confidence interval if the $p<0.05 . P<0.05$ was considered statistically significant. All data were analyzed in Statistic Package for Social Science (SPSS) version 19.0 (SPSS Inc., Chicago, USA).

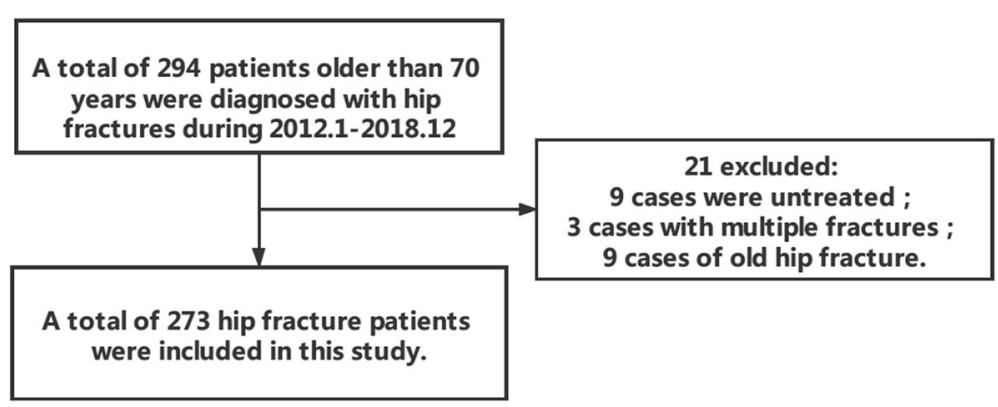

Fig. 1 Exclusion criteria and the number of studies were included in this study 


\section{Results}

\section{Clinical characteristics}

All patients had an average age of $78 \pm 11$ years, and $57 \%$ were women. Among the 273 patients, 1 underwent surgery within $24 \mathrm{~h}, 16$ within $48 \mathrm{~h}, 57$ within $72 \mathrm{~h}$ and the 199 more than $72 \mathrm{~h}$. The mean time to surgery was $99.6 \pm 22.1 \mathrm{~h}$. There were $3.4 \%$ of patients with surgery within the $48 \mathrm{~h}$ after the fracture. Fifteen patients (5.6\%) had limb DVT (10 cases were peripheral type, and 5 cases were central type). Two of the DVT (1 peripheral type and 1 central type) occurred $48 \mathrm{~h}$ before surgery, and the other 13 occurred after $48 \mathrm{~h}$ from the time of hip fracture. No PE occurred in the perioperative period.

\section{Univariate analyses}

In the univariate analysis, fracture to surgery time, preoperative hemoglobin level, anemia, pulmonary disease, preoperative hospitalization and total hospitalization time were statistically different between DVT group and non-DVT group $(P<0.05$ for all). There were no statistical difference between two groups in age, sex, diabetes, hypertension, stroke, ischemic heart disease, arrhythmia, whether transfusion, congestive heart failure, postoperative hospitalization, international normalized ratio (INR) and ESR $(P>0.05)$ (Table 1$)$.

\section{Multivariate analyses}

Multivariate logistic regression analyses confirmed that preoperative anemia (OR: 0.144, 95\% CI: 0.026-0.799, $P=0.027$ ) and total hospitalization time (OR: 1.135; 95\%CI: $1.023-1.259, P=0.017)$ were the two independent risk factors for preoperative DVT (Table 2).

\section{Discussion}

This study demonstrated that the overall incidence of DVT after hip fracture was 5.6\%, and no PE occurred in all patients. In addition, multivariate logistic regression analyses indicated that preoperative anemia and total hospitalization time were the independent risk factors for preoperative DVT after hip fracture.

Hip fracture is one of the most common orthopedic conditions. The risk of VTE in patients with hip fracture is substantial, which is the second most frequent complication of surgery. Reboerts et al. [3] and Hefley et al. [4] have reported that the incidence of DVT was about 6-9\% in patients with hip fracture. In addition, Wong et al. [10] have been reported that the incidence of VTE was $6.4 \%$ after proximal hip fracture in Singapore. Mok et al. [11] have also reported that the incidence of VTE was $8 \%$ after proximal hip fracture in Hong Kong. All above results are the same to our results. Furthermore, delayed surgery for these kinds of patients is known to be one of the most important factors contributing to the high incidence of preoperative DVT [4]. Hip fracture surgery should be performed within $48 \mathrm{~h}$ after fracture [12]. However, in clinical work, targeting within the $48 \mathrm{~h}$, even in the $24 \mathrm{~h}$, represents a significant change in practice because $66 \%$ of the patients did not receive surgery within time frame [13]. Only $3.4 \%$ of patients in our study completed surgery within $48 \mathrm{~h}$ after fracture, because the multi-disciplinary consultation and preoperative evaluation are often required owing to the prevalence of severe comorbidities in these patients but assessing appropriately.

The incidence of anemia at admission in individuals with hip fracture is high, varying from $12.3 \%$ with hemoglobin level less than $10 \mathrm{~g} / \mathrm{dL}$ to $40.4 \%$ with hemoglobin level less than $12 \mathrm{~g} / \mathrm{dL}$ [14]. Anemia is associated with increased mortality, increase VTE risk, prolong admission, higher readmission rate and increased mortality rate in patients with hip fracture [15-20]. Furthermore, most patients in this study often had cardiovascular disease (28\%) before surgery, which reminded that we should actively correct a severely decreased preoperative hemoglobin of less than 9 during perioperative low hemoglobin in order to reduce the risk of cardiovascular events. Because the most frequent cause of death after hip fracture surgery is cardiovascular diseases [21]. The lower hemoglobin level at admission is not owing to bleeding from trochanteric fracture, but reflects the anemia before the injury. It is known that the anemia and low hemoglobin concentrations were significantly associated with frailty [22]. Frailty has been shown to predict adverse outcomes in older surgical patients, which is related with more postoperative complications, length of stay, and greater morbidity and mortality [22-25] . However, frailty is a common status among hip fracture patients and seriously affect quality of life on these patients [23, 24]. Chen et al. [25] study found that the frailty state of elderly patients with hip fracture surgery can significantly increase major adverse events, including mortality, readmission, and postoperative emergency room visits. Inoue et al. [26] also pointed that the frailty can be assessed as a predict short-term functional recovery during the acute phase in patients with hip fracture. Therefore, early identification of prefracture frailty in patients with a hip fracture is important for prognostic counselling, care planning and the tailoring of treatment [27].

The total estimated number of hip fracture in Asian countries will increase from 1.12 million in 2018 to 2.56 million in 2050 [28]. Hip fractures are related to increased morbidity and adverse clinical outcomes during hospitalization and discharge are common and costly occurrences [29]. It is logical to perform surgery as early as possible (Best within $48 \mathrm{~h}$ after hip fracture) in order to avoid these complications, especially to reduce the risk of VTE. Optimal strategies for thromboprophylaxis after hip fracture also include use one of the following antithrombotic prophylaxis (Low molecular weight heparin, Fondaparinux, Low dose unfractionated heparin, et al) 
Table 1 Factors associated with the development of perioperative DVT

\begin{tabular}{|c|c|c|c|}
\hline Variables & DVT group & Non- DVT group & $\boldsymbol{P}$ value \\
\hline Age(mean years $\pm S D)$ & $78 \pm 4$ & $78 \pm 5$ & 0.911 \\
\hline Male sex (\%) & 2 & 70 & 0.330 \\
\hline $\mathrm{BMI}($ mean $\pm \mathrm{SD})$ & $22.9 \pm 4.1$ & $23.1 \pm 4$ & 0.910 \\
\hline $\mathrm{EF}(\%)$ & $60.5 \pm 1.1$ & $60.6 \pm 3.7$ & 0.661 \\
\hline \multicolumn{4}{|l|}{ Comorbidities } \\
\hline Hypertension & 5 & 117 & 0.303 \\
\hline Coronary artery disease & 1 & 42 & 0.478 \\
\hline Diabetes & 3 & 58 & 0.529 \\
\hline Arrhythmia & 2 & 32 & 0.600 \\
\hline Cerebral infarction & 2 & 32 & 0.583 \\
\hline Pulmonary disease & 3 & 15 & 0.074 \\
\hline Anemia & 13 & 133 & 0.014 \\
\hline $\mathrm{PH}($ mean $\pm \mathrm{SD})$ & $7.43 \pm 0.02$ & $7.49 \pm 1.22$ & 0.861 \\
\hline $\mathrm{Hb}($ mean $\pm \mathrm{SD})$ & $107.1 \pm 10.1$ & $115.6 \pm 18.7$ & 0.007 \\
\hline $\mathrm{PCO}_{2}($ mean $\pm \mathrm{SD})$ & $37.7 \pm 4.4$ & $39.8 \pm 5.7$ & 0.212 \\
\hline $\mathrm{PO}_{2}($ mean $\pm \mathrm{SD})$ & $76.2 \pm 9.6$ & $75.9 \pm 17.9$ & 0.490 \\
\hline D-dimer(mean \pm SD) & $4860 \pm 7824$ & $3373 \pm 7380$ & 0.095 \\
\hline $\mathrm{ESR}($ mean $\pm \mathrm{SD})$ & $42.0 \pm 18.6$ & $33.9 \pm 19.7$ & 0.113 \\
\hline \multicolumn{4}{|l|}{ ASA classification } \\
\hline$|-| \mid$ & 6 & 106 & 0.814 \\
\hline III-IV & 9 & 143 & 0.814 \\
\hline \multicolumn{4}{|l|}{ Anesthesia method } \\
\hline General anesthesia & 2 & 46 & 0.859 \\
\hline Epidural anesthesia & 0 & 16 & 0.609 \\
\hline Regional nerve block & 10 & 151 & 0.892 \\
\hline General + nerve block & 3 & 33 & 0.443 \\
\hline Injure to operation time(day) & $18.1 \pm 12.1$ & $13.7 \pm 36.3$ & 0.002 \\
\hline \multicolumn{4}{|l|}{ Type of operation } \\
\hline Hip replacement & 1 & 25 & 1.000 \\
\hline Femoral head replacement & 4 & 93 & 0.386 \\
\hline Bone nail & 10 & 128 & 0.270 \\
\hline Operation time(min) & $103.1 \pm 53.4$ & $99.7 \pm 47.4$ & 0.901 \\
\hline Preoperative hospitalization(day) & $8.1 \pm 3.2$ & $6.4 \pm 3.2$ & 0.039 \\
\hline Postoperative hospitalization(day) & $12.4 \pm 4.5$ & $10.0 \pm 6.4$ & 0.159 \\
\hline In-hospital time(day) & $20.5 \pm 4.5$ & $16.5 \pm 7.3$ & 0.001 \\
\hline Blood loss(ml) & $365 \pm 464$ & $258 \pm 220$ & 0.898 \\
\hline Whether transfusion & 2 & 36 & 0.904 \\
\hline
\end{tabular}

BMI Body mass index, ASA American society of anesthesiology, ESR Erythrocyte sedimentation rate, EF Ejection fraction

for a minimus of 10 and/or 14 days, or an intermittent pneumatic compression device [30]. In addition to above measures, more and more evidence have suggested that comprehensive geriatric assessment decreased the risks of complications after hip fracture [31], which is not delaying surgery but assessing appropriately. Kammerlander et al. [32] have been pointed out that the interdisciplinary team could achieve the lowest in-hospital 
Table 2 Multivariate logistic regression analysis

\begin{tabular}{llll}
\hline Risk factors & OR & $95 \% \mathrm{Cl}$ & $\boldsymbol{P}$ value \\
\hline Hemoglobin level & 0.965 & $0.93-1.001$ & 0.056 \\
The length of stay & 1.135 & $1.023-1.259$ & 0.017 \\
Pulmonary disease & 1.135 & $0.117-10.973$ & 0.913 \\
D-dimer & 1.000 & $1.000-1.000$ & 0.081 \\
Injure to surgery time & 1.005 & $0.984-1.026$ & 0.670 \\
Anemia & 0.144 & $0.026-0.799$ & 0.027 \\
Preoperative hospitalization & 1.129 & $0.987-1.292$ & 0.076 \\
\hline
\end{tabular}

$O R$ Odds ratio, $\mathrm{Cl}$ Confidence interval

${ }^{*} P<0.05$ was considered statistically significant

mortality rate (1.14\%), the lowest hospitalization time (7.39 days) and the lowest mean time to surgery (1.43 days). Besides, comanaged geriatric fracture center program that has resulted in lower than the predicted hospitalization time and readmission rates, with short time to surgery, low complication rates and low mortality $[33,34]$. A previous study has also pointed out that the mean postoperative length of stay was 5 days in the USA and 34 days in the Japan, and the risk of death after hospital discharge was doubled in the USA in comparison with Japan [35]. Because shorter length of stay after hip fracture is associated with increased risk of death after hospital discharge, but only among patients with length of stay of 10 days or less [36]. Therefore, it is prudent to prolonged hospital stay for patients at high risks after hip fracture surgery. Furthermore, European and North American studies have also shown that care provision by more nurses with at least bachelor's degrees are associated with lower mortality after surgery [37, 38]. Physical therapy also important to enhance functional capacity and postpone the need for institutional care, and diminish the use of social and health care services for the older with signs of frailty or with a recent hip fracture [39].

\section{Limitations}

Our study has some limitations. First, this study was a single-center retrospective analysis and all data were retrospectively collected. A multi-center randomized controlled trial is needed in the future. Second, only $5.6 \%$ of patients in this study were found to have DVT before surgery, some maybe were missed on ultrasonography. Third, our study not evaluate the postoperation and long term morbidity, such as the arrhythmia, myocardial infarction and pneumonia. Four, this study not mention the importance of physical therapy for reduce the incidence and severity of frailty and mortality.

\section{Conclusion}

In order to reduce the risk of DVT, it is currently agreed that elderly hip fracture patients should be operated as soon as possible, preferably within $48 \mathrm{~h}$ after the fracture.
However, for critically ill patients, comprehensive geriatric assessment is not about delaying surgery but assessing appropriately. Besides, cardiovascular diseases are often associated with such patients before operation. Active correction of severe anemia of $<9$ and frailty is also beneficial to reduce the risk of cardiovascular events, morbidity and mortality during perioperative period. In addition, prevention and minimize the risk of DVT after postoperatively should be mobilization with active physical therapy, chemical prophylaxis against VTE (such as Low molecular weight heparin, et al) for a minimus of 10 to 14 days, and surveillance with screening ultrasonographies. For highrisk patients, the length of hospital stay should be appropriately extended, and aggressive postoperative medical care and physical therapy also should be received.

\section{Abbreviations \\ DVT: Deep vein thrombosis; VTE: Venous thromboembolism; ASA: American Society of Anesthesiologists; PE: Pulmonary embolism; ESR: Erythrocyte sedimentation; BMI: Body mass index; Hb: Hemoglobin; EF: Ejection fraction}

\section{Acknowledgments}

None.

\section{Authors' contributions}

$\mathrm{HZ}$ and $\mathrm{ZGF}$ contributed to the design of the study and the review of the literature. LF, WXY, LHX, ZPX participated in data collection, analysis and drifting of the manuscript. The authors read and approved the manuscript.

\section{Funding}

This investigation was supports by Grants 13BJZ38 awarded by the "Health Special Scientific Research Project. This investigation also was supports by grants 2018YW16 awarded by the Sanya Medical and Health Science and Technology Innovation Project.

\section{Availability of data and materials}

The datasets used and/or analysed during the current study are not publicity available. All data are available from the corresponding author upon reasonable request.

\section{Ethics approval and consent to participate}

The study was approved by the ethical committee of the Chinese People's Liberation Army General Hospital.

Consent for publication

Not applicable.

\section{Competing interests}

The authors declare that they have no competing interests.

\section{Author details}

${ }^{1}$ Medicine School of Chinese PLA, No.28, Fuxing Road, Beijing 100853, China. 2Department of Anesthesia, Hainan Hospital of Chinese PLA General Hospital, No.80, Jianglin Road, Sanya 572000, China. ${ }^{3}$ Department of Anesthesia

Operation Center, Chinese PLA General Hospital, No.28, Fuxing Road, Beijing 100853, China.

Received: 21 July 2019 Accepted: 10 March 2020

Published online: 02 April 2020

\section{References}

1. Rathbun S. The surgeon general's call to action to prevent deep vein throm-bosis and pulmonary embolism. Circulation. 2009;119(15):e480-2.

2. Marsland D, Mears SC, Kates SL. Venous thromboembolic prophylaxis for hip fractures. Osteoporos Int. 2010;21(Suppl 4):S593-604. 
3. Roberts TS, Nelson CL, Barnes CL, Ferris El, Holder JC, Boone DW. The preoperative prevalence and postoperative incidence of thromboembolism in patients with hip fractures treated with dextran prophylaxis. Clin Orthop Relat Res. 1990;255:198-203.

4. Hefley FG Jr, Nelson CL, Puskarich-May CL. Effect of delayed admission to the hospital on the preoperative prevalence of deep-vein thrombosis associated with fractures about the hip. J Bone Joint Surg Am. 1996;78(4):581-3.

5. Brauer CA, Coca-Perraillon M, Cutler DM, Rosen AB. Incidence and mortality of hip fractures in the United States. JAMA. 2009;302(14):1573-9.

6. Pedersen AB, Ehrenstein V, Szépligeti SK, Sørensen HT. Excess risk of venous thromboembolism in hip fracture patients and the prognostic impact of comorbidity. Osteoporos Int. 2017;28(12):3421-30.

7. Parviz J, Huang R, Raphael U, Amold WW, Rothman RH. Symptomatic pulmonary embolus after joint arthroplasty. stratification of risk factors. Clin Orthop Relat Res. 2014;472(3):903-12.

8. Shahi A, Chen AF, Tan TL, Maltenfort MG, Kucukdurmaz F, Parvizi J. The incidence and economic burden of in-hospital venous thromboembolism in the United States. J Arthroplasty. 2017;32(4):1063-6.

9. Rabinov K, Paulin S. Roentgen diagnosis of venous thrombosis in the leg. Arch Surg. 1972;104(2):134-44.

10. Wong KL, Daruwalla ZJ, Lan CJ, Tan SH, Shen L, Chua W, et al. Postoperative venous thrombotic events in Asian elderly patients with surgically treated hip fractures with and without chemoprophylaxis. Hip Int. 2014;24(6):650-5.

11. Mok CK, Hoaglund FT, Rogoff SM, Chow SP, Ma A, Yau AC. The incidence of deep vein thrombolisis in Hong Kong chinese after hip surgery for fracture of the proximal femur. Br J Surg. 1979;66(9):640-2.

12. Bhandari M, Swiontkowski M. Management of acute hip fracture. N Engl J Med. 2017;377(21):2053-62.

13. Pincus D, Ravi B, Wasserstein D, Huang A, Paterson JM, Nathens AB, et al. Association between wait time and 30-day mortality in adults undergoing hip fracture surgery. JAMA. 2017;318(20):1994-2003.

14. Halm EA, Wang JJ, Boockvar K, Penrod J, Silberzweig SB, Magaziner J, et al. The effect of perioperative anemia on clinical and functional outcomes in patients with hip fracture. J Orthop Trauma. 2004;18(6):369-74.

15. Bhaskar D, Parker MJ. Haematological indices as surrogate markers of factors affecting mortality after hip fracture. Injury. 2011:42(4):178-82.

16. Hagino T, Ochiai S, Sato E, Maekawa S, Wako M, Haro H. The relationship between anemia at admission and outcome in patients older than 60 years with hip fracture. J Orthop Traumatol. 2009;10(3):119-22.

17. Foss NB, Kristensen MT, Kehlet $H$. Anaemia impedes functional mobility after hip fracture surgery. Age Ageing. 2008;37(2):173-8.

18. Smith EB, Parvizi J, Purtill JJ. Delayed surgery for patients with femur and hip fractures-risk of deep venous thrombosis. J Trauma. 2011;70(6):E113-6.

19. Sim YE, Sim SD, Seng C, Howe TS, Koh SB, Abdullah HR. Preoperative anemia, functional outcomes, and quality of life after hip fracture surgery. J Am Geriatr Soc 2018,66(8):1524-31.

20. Abdullah HR, Sim YE, Hao Y, Lin GY, Liew GHC, Lamoureux EL, et al. Association between preoperative anaemia with length of hospital stay among patients undergoing primary total knee arthroplasty in Singapore: a single-Centre retrospective study. BMJ Open. 2017;7(6):e016403.

21. Rosencher N, Vielpeau C, Emmerich J, Fagnani F, Samama CM. Venous thromboembolism and mortality after hip fracture surgery: the ESCORTE study. J Thromb Haemost. 2005;3(9):2006-14.

22. Ruan Y, Guo Y, Kowal P, Lu Y, Liu C, Sun S, et al. Association between anemia and frailty in 13,175 community-dwelling adults aged 50 years and older in China. BMC Geriatr. 2019;19(1):327.

23. Gleason LJ, Benton EA, Alvarez-Nebreda ML, Weaver MJ, Harris MB, Javedan $H$. FRAlL questionnaire screening tool and short-term outcomes in geriatric frac- ture patients. J Am Med Dir Assoc. 2017;18(12):1082-6.

24. Kua J, Ramason R, Rajamoney G, Chong MS. Which frailty measure is a good predictor of early post-operative complications in elderly hip fracture patients? Arch Orthop Trauma Surg. 2016;136:639-47.

25. Chen $\mathrm{CL}$, Chen $\mathrm{CM}$, Wang $\mathrm{CY}, \mathrm{Ko}$ PW, Chen $\mathrm{CH}$, Hsieh CP, et al. Frailty is associated with an increased risk of major adverse outcomes in elderly patients following surgical treatment of hip fracture. Sci Rep. 2019;9(1):19135.

26. Inoue T, Misu S, Tanaka T, Kakehi T, Kakiuchi M, Chuman Y, Ono R. Frailty defined by 19 items as a predictor of short-term functional recovery in patients with hip fracture. Injury. 2019;50(12):2272-6.

27. Van de Ree CLP, Landers MJF, Kruithof N, de Munter L, Slaets JPJ, Gosens T, et al. Effect of frailty on quality of life in elderly patients after hip fracture: a longitudinal study. BMJ Open. 2019;9(7):e025941.

28. Cheung CL, Ang SB, Chadha M, Chow ES, Chung YS, Hew FL, et al. An updated hip fracture projection in Asia: the Asian Federation of Osteoporosis Societies study. Osteoporos Sarcopenia. 2018;4(1):16-21.
29. Lin JC, Liang WM. Mortality, readmission, and reoperation after hip fracture in nonagenarians. BMC Musculoskelet Disord. 2017;18(4):144

30. Falck-Ytter Y, Francis CW, Johanson NA, Curley C, Dahl OE, Schulman S, et al. Prevention of VTE in orthopedic surgery patients: antithrombotic therapy and prevention of thrombosis, 9th ed: American College of Chest Physicians Evidence-Based Clinical Practice Guidelines. Chest. 2012;141(2 Suppl):e278S-325S.

31. Vidán M, Serra JA, Moreno C, Riquelme G, Ortiz J. Efficacy of a comprehensive geriatric intervention in older patients hospitalized for hip fracture: a randomized, controlled trial. J Am Geriatr Soc. 2005;53(9):1476-82

32. Kammerlander C, Roth T, Friedman SM, Suhm N, Luger TJ, KammerlanderKnauer U, et al. Ortho-geriatric service-a literature review comparing different models. Osteoporos Int. 2010;21(4):S637-46.

33. Bukata SV, DiGiovanni BF, Friedman SM. A guide to improving the care of patients with fragility fractures. Geriatr Orthop Surg Rehabil. 2011;2(1):5-37.

34. Friedman SM, Mendelson DA, Kates SL, McCann RM. Geriatric comanagement of proximal femur fractures: total quality management and protocol-driven care result in better outcomes for a frail patient population. J Am Geriatr Soc. 2008;56(7):1349-56.

35. Kondo A, Zierler BK, Isokawa Y, Hagino H, Ito Y, Richerson M. Comparison of lengths of hospital stay after surgery and mortality in elderly hip fracture patients between Japan and the United States - the relationship between the lengths of hospital stay after surgery and mortality. Disabil Rehabil. 2010;32(10):826-35.

36. Nordstrom P, Gustafson Y, Michaelsson K, Nordström A. Length of hospital stay after hip fracture and short term risk of death after discharge: a total cohort study in Sweden. BMJ. 2015;7(6):350-e016430.

37. Aiken LH, Clarke SP, Sloane DM, Sochalski J, Silber JH. Hospital nurse staffing and patient mortality, nurse burnout, and job dissatisfaction. JAMA. 2002; 288(16):1987-93.

38. Rafferty AM, Clarke SP, Coles J, Ball J, James P, McKee M. Outcomes of variation in hospital nurse staffing in English hospitals: cross-sectional analysis of survey data and discharge records. Int J Nurs Stud. 2007:44(2):175-82.

39. Soukkio P, Suikkanen S, Kääriä S, Kautiainen H, Sipilä S, Kukkonen-Harjula K, et al. Effects of 12-month home-based physiotherapy on duration of living at home and functional capacity among older persons with signs of frailty or with a recent hip fracture - protocol of a randomized controlled trial (HIPFRA study). BMC Geriatr. 2018;18(1):232.

\section{Publisher's Note}

Springer Nature remains neutral with regard to jurisdictional claims in published maps and institutional affiliations.

Ready to submit your research? Choose BMC and benefit from

- fast, convenient online submission

- thorough peer review by experienced researchers in your field

- rapid publication on acceptance

- support for research data, including large and complex data types

- gold Open Access which fosters wider collaboration and increased citations

- maximum visibility for your research: over $100 \mathrm{M}$ website views per year

At $\mathrm{BMC}$, research is always in progress.

Learn more biomedcentral.com/submissions 